\title{
Hautamäki, Antti. Viewpoint Relativism: a new approach to epistemological relativism based on the concept of points of view. Suiza: Springer, Synthese Library 419, 2020, 210 pp.
}

\author{
Enrico Brugnami' \\ Universidad de la Laguna, Tenerife, España
}

El relativismo es quizás uno de los temas de discusión más antiguos y que más ha tratado la filosofía a lo largo de su historia, tanto directa como indirectamente. Desde el panta rei heraclíteo y el homo mensura protagóreo hasta los actuales desarrollos postmodernos de la sociedad líquida y la posverdad, el relativismo ha constituido un problema central e irresoluble.

La obra que aquí nos ocupa, Viewpoint Relativism, hace del relativismo su objeto central de estudio. Pero lejos de ser un simple resumen de lo que ha sido y es el relativismo, ofrece un análisis fresco y actual del mismo a la luz de una metafísica y epistemología perspectivistas. Su tesis principal parte del rechazo de toda forma de relativismo universal y extremo, pues es considerado como autocontradictorio. Postula como teoría filosófica, en cambio, un relativismo perspectivista, local y acotado según el cual toda cuestión epistémica es dependiente de una perspectiva o punto de vista.

$\mathrm{Su}$ autor es Antti Hautamäki (Finlandia, 1949), profesor emérito de las universidades de Helsinki y Jyväskylä. Se doctoró en el 1987 bajo la dirección de Raimo Tuomela con una tesis sobre el análisis lógico de los puntos de vista. Tanto el relativismo como el perspectivismo han sido y siguen siendo cuestiones centrales en la trayectoria académica de Hautamäki, pero sus intereses son mucho más extensos, abarcando temas como el desarrollo y la innovación sostenibles, el bienestar social o el manejo de la 
información y el conocimiento en la sociedad.

Viewpoint Relativism es un ensayo filosófico de estilo académico en el cual su autor imprime una voluntad de ser claro, legible y útil para toda persona que tenga una formación básica en filosofía. La obra está compuesta de ocho capítulos: (1) Trasfondo histórico del relativismo, (2) Condiciones para la discusión filosófica, (3) Puntos de vista y relativismo, (4) La relatividad de la verdad, (5) La relatividad del conocimiento, (6) La relatividad de la realidad, (7) Relativismo y realismo en la filosofía de la ciencia y (8) Relativismo crítico y desacuerdo.

Sin embargo, podemos estructurar la obra en dos partes: una primera parte de fundamentación y exposición general de la teoría y una segunda parte de aplicación de dicha teoría a distintos objetos. Así, la primera parte está compuesta por los tres primeros capítulos, ofreciendo una fundamentación histórica (capítulo 1) y conceptual (capítulo 3) del relativismo perspectivista y una reflexión metafilosófica acerca de las condiciones para la discusión e investigación filosóficas (capítulo 2). La segunda parte está compuesta por los capítulos restantes, aplicando su propuesta de relativismo perspectivista al análisis de la verdad (capítulo 4), el conocimiento (capítulo 5), la realidad (capítulos 6 y 7) y la posverdad y el desacuerdo epistémico (capítulo 8). Dado que en esta reseña buscamos ofrecer al lector una visión general y panorámica de la obra atendiendo a su tesis principal, nos centraremos especialmente en los capítulos 2 y 3 , sin perder de vista el resto del libro.

Es notable encontrar en un ensayo académico una reflexión clara y directa acerca de la definición de filosofía. En Viewpoint Relativism entiende Hautamäki la filosofía como la actividad de definir e interpretar conceptos. Sustentar una teoría filosófica es, pues, tomar una determinada posición respecto de la definición e interpretación de uno o varios conceptos claves (p.14). Hay distintas maneras de definir e interpretar conceptos filosóficos y nada puede decirnos qué interpretación es la correcta de una manera definitiva. Sin embargo, esto no lleva a una situación de relativismo extremo e inconmensurable, sino que cabe la posibilidad de comparar distintas teorías y seleccionar las que sean más relevantes.

Este proceso de comparación entre distintas posiciones teóricas o puntos de vista es lo propio de la investigación filosófica, y sólo puede lle- 
varse a cabo mediante la discusión racional. Según Hautamäki, una discusión es racional cuando es guiada por la voluntad de formar argumentos válidos a favor o en contra de una tesis (p. 21). Que pueda haber una comparación entre puntos de vista distintos mediante un acto de discusión racional y que pueda llegarse a un estado de acuerdo o desacuerdo epistémico supone, para el autor, la existencia de un tipo de racionalidad que, sin ser universal ni atemporal (p. 24), debe ser común a todos los puntos de vista. Esta es la denominada racionalidad central (core rationality).

La racionalidad central que defiende Hautamäki está caracterizada por la consistencia dentro de un mismo punto de vista (pues que una aserción sea verdadera en un punto de vista y falsa en otro no constituye una contradicción), la capacidad de inferencialidad deductiva e inductiva y la aceptación o rechazo de una teoría sólo en función de la evidencia que la soporta. Todo sistema de creencias creado a partir de esta racionalidad central es, pues, un sistema consistente, cerrado por una clausura deductiva y apoyado empíricamente mediante la inducción (p. 23).

Junto a esta racionalidad central, un hecho que nos ayuda a alcanzar acuerdos y desacuerdos en situaciones de pluralismo epistémico es que todos los sujetos partícipes de la discusión e investigación filosófica realicen unas determinadas asunciones comunes. Tales asunciones son la existencia de un mundo común (Mundo-C) o realidad común (Realidad-C), el uso de un lenguaje común (Lenguaje-C) y el manejo de una concepción común de la verdad (Verdad-C). Estos tres elementos conforman lo que el autor denomina una teoría común (Teoría-C), útil para que pueda darse una discusión filosófica fructífera.

Resulta muy interesante a nivel metafilosófico la postulación de una Teoría-C como condición para el acuerdo y desacuerdo epistémico, además de retrotraernos a nociones básicas de la fenomenología y la hermenéutica como son mundo de la vida y pre-entendimento. Sin embargo, no ahondaré en dicha teoría, pues el propio Hautamäki advierte que es inferencial y conceptualmente independiente del relativismo perspectivista (pp. 26 y 191) y, por lo tanto, prescindible para la defensa de dicha postura filosófica.

El relativismo perspectivista puede resumirse en las siguientes seis tesis (p. 37):

1. Nuestra única manera de acceder a la realidad es mediante un punto 
de vista.

2. Los puntos de vista son subjetivos en tanto que son tenidos por un sujeto, pero se objetivan al apuntar a una realidad exterior al sujeto y al darse en un lenguaje común.

3. Cada objeto puede ser considerado desde distintos puntos de vista.

4. No hay un punto de vista absoluto ni privilegiado.

5. Los puntos de vista deben poder mejorar y cambiar.

6. Pueden usarse distintos tipos de criterios para comparar los puntos de vista.

Mediante cada una de estas tesis se está posicionando el relativismo perspectivista frente a diversas teorías y posiciones filosóficas. En concreto, las seis tesis rechazan, respectivamente, el realismo, el subjetivismo, el monismo, el absolutismo, el platonismo y el relativismo extremo (p. 38).

El concepto común a estas seis tesis y que es central en el libro es, como ya se ha dicho, el de punto de vista. Hautamäki se apoya en dos definiciones similares de punto de vista para ofrecer, posteriormente, la suya propia. La primera definición que contempla es la propuesta por Manuel Liz y Margarita Vázquez. Según dicha propuesta, un punto de vista tiene como sus elementos estructurales un portador o titular del punto de vista, un contenido (conceptual o no conceptual), una relación que conecta al portador con el contenido y una condición de posesión del punto de vista por parte del portador (pp. 40-41). La segunda definición que contempla es la de Tommi Lehtonen, cercana a la de Manuel Liz y Margarita Vázquez, según la cual un punto de vista contiene un sujeto, un objeto y un método o herramienta mediante la cual el sujeto accede epistémicamente al objeto.

A tenor de ambas definiciones, Hautamäki formula la siguiente: un punto de vista lo es sí y sólo sí un aspecto de un objeto representa dicho objeto a un sujeto (p.43). Es decir, un punto de vista está conformado siempre por un sujeto y un objeto epistémicos, y la parte del objeto que el sujeto selecciona en su representación es el aspecto del objeto.

Esta concepción de punto de vista (que obviamente es mucho más amplia de la explicada aquí) permite al autor aplicar su relativismo perspectivista a varios problemas con los que el relativismo tradicional se ha enfrentado. Entre ellos, están el relativismo de la verdad (relativismo alético), del conocimiento (relativismo epistémico) y de la realidad (relativismo 
conceptual).

Respecto de la verdad afirma Hautamäki que siempre se da en un determinado contexto. Forman parte de este contexto los puntos de vista mediante los cuales un sujeto accede a un determinado aspecto de la realidad. Así pues, según la teoría del relativismo perspectivista, una proposición $p$ es verdadera desde un punto de vista $P$ si $p$ es verdadera respecto del objeto al que apunta (interpretando dicho objeto como el aspecto mostrado en el punto de vista) (p. 90).

Respecto del conocimiento, el autor se centra en la noción de Clarence Irving Lewis. Según Lewis, el conocimiento es una función cuyo resultado depende de dos variables: el sujeto y el objeto de conocimiento. En conjunción con el relativismo perspectivista, Hautamäki incluye los puntos de vista como variables de la función, haciendo que el conocimiento sea dependiente de los puntos de vista que el sujeto tenga respecto del objeto. El conocimiento, desde esta teoría, no puede ser justificado atendiendo a criterios objetivos y universales, sino tan solo criterios locales dependientes del sistema de creencias en el que se esté (p. 112).

Respecto de la realidad, y en concordancia con el relativismo del conocimiento, Hautamäki señala que un punto de vista lo que hace es ofrecer un mapeado o estructuración del mundo. Cada mapa o estructura depende de la adopción de un punto de vista determinado. La realidad es estructurada (no creada) por el sujeto mediante la adopción de un punto de vista. Verdad, conocimiento y realidad son, como vemos, elementos interconectados y dependientes de la noción más básica y fundamental de punto de vista.

En conclusión, podemos decir que Viewpoint Relativism ofrece una mirada muy actual a un problema clásico de la filosofía como es el relativismo. Su claridad no resta profundidad al contenido. Creo que el autor consigue con esta obra ofrecer una visión amplia del relativismo adecuada para el estudiante recién graduado $y$, a su vez, una vía vigente y relevante de investigación para el filósofo profesional. Es por este doble carácter didáctico y útil por el que creo que puede resultar interesante para toda persona que se interese por el relativismo y los puntos de vista. 